\title{
Adaptive Plasticity of Xenopus Glial Cells In Vitro and After CNS Fiber Tract Lesions In Vivo
}

\author{
DIRK M. LANG AND CLAUDIA A.O. STUERMER \\ Faculty of Biology, University of Konstanz, D-78434 Konstanz, Germany
}

\begin{abstract}
KEY WORDS Oligodendrocytes, Differentiation, Optic nerve, Spinal cord
\end{abstract}
\begin{abstract}
Xenopus oligodendrocytes and aspects of their differentiation were analyzed in vitro and in vivo using cell- and stage-specific antibodies. Undifferentiated oligodendrocytes were derived from optic nerves or spinal cords. They divided in vitro, were of elongated shape, were glial fibrillary acidic protein and $\mathrm{O} 4$ positive, transiently exhibited several antigens including HNK-1 and L1, and promoted axon growth as do Schwann cells. With forskolin they differentiated and, much like myelin-forming oligodendrocytes in the intact optic nerve and spinal cord, they expressed sets of advanced myelin markers. These advanced myelin markers disappeared from the regenerating optic nerve 4 weeks after lesion. The optic nerve instead was populated by cells with radial processes and somata in the center of the nerve; among them were cells and processes that were $\mathrm{O} 4$ positive and that are suspected to represent undifferentiated oligodendrocytes. Where processes of these cells reached to the retinal axons in the nerve's periphery, advanced myelin markers typical of differentiated oligodendrocytes reappeared 8 weeks after lesion. These glial changes did not occur in the absence of retinal axons. Thus, the apparent capability of Xenopus oligodendrocytes to adapt to the transient absence, reappearance, and regenerative state of the axons enables them to contribute to central nervous system fiber tract repair. This occurs in the lesioned optic nerve but not in the spinal cord, where no such glial changes were observed and where axons fail to regenerate.
\end{abstract}

\section{INTRODUCTION}

The glial cell contribution to success or failure of axon regeneration has been recognized in a variety of species and systems. Axon regeneration is successful in the vertebrate peripheral nervous system (PNS) where regrowth of axons is promoted by Schwann cells (Bunge and Hopkins, 1990) but fails in the central nervous system (CNS) of mammals and birds where oligodendrocytes and reactive astrocytes impair axon regrowth (Reier and Houle, 1988; Schwab et al., 1993). The growth-inhibiting influence of CNS glia is also present in the spinal cord of the frog Xenopus (Lang et al., 1995) and correlates-as in mammals - with lack of axon regrowth, but is absent from the Xenopus visual system (Lang et al., 1995) and from the fish CNS (Bastmeyer et al., 1991; Wanner et al., 1995). Accordingly, in both the CNS of fish and the visual system of amphibians, lesioned axons regenerate successfully (Gaze, 1970). In the case of fish, oligodendrocytes apparently adapt to the state of the axons (Ankerhold et al., 1995) much like Schwann cells in mammalian PNS. Schwann cells and fish oligodendrocytes are capable of dedifferentiating upon axon injury, of providing growth-supportive molecules, and of subsequently redifferentiating for axon remyelination (Bastmeyer et al., 1993, 1994; Bunge, 1993; Schwalb et al., 1996; Wolburg, 1981). The expression of proteins involved in myelination is induced by axon contact, and this expression can, in the

\footnotetext{
Received February 13, 1996; accepted May 24, 1996.

Address reprint requests to Claudia A.O. Stuermer, Faculty of Biology, University of Konstanz, D-78434 Konstanz, Germany.
} 
case of Schwann cells, be simulated by agents (e.g., forskolin) that elevate the intracellular concentration of cAMP (Lemke and Chao, 1988; Morgan et al, 1991). As regenerated axons in vivo become remyelinated, the lesioned systems can recover their proper functions. Such an adaptation to the state of the system is not observed in oligodendrocytes of mammals. Oligodendrocytes in the adult mammalian CNS appear to be less responsive to the state of the axons (Raff and Miller, 1984) and fail to undergo the range of changes observed in Schwann cells and fish oligodendrocytes in response to axon lesion. Thus, repair of lesioned fiber tracts including axon regeneration and remyelination is paralleled by and may therefore depend on timely responses of glial cells as exemplified by Schwann cells and fish oligodendrocytes.

Since retinal axons do regenerate in frogs and restore vision, glia in optic nerves of frogs are therefore expected to respond to deprivation from axons, to assist axonal regrowth, and to be capable of remyelination. That Xenopus glial cells indeed undergo changes when the optic nerve is severed has in fact been demonstrated earlier (Bohn and Reier, 1985; Reier and Webster, 1974). The somata of Xenopus glial cells cluster in the center of the nerve and, reminiscent of radial or ependymoglia, extend long centroperipherally oriented processes to the outer perimeter. The regenerating axons take abnormal routes in that they course through the periphery of the nerve and orthogonally to the glial processes. The regenerated axons later become remyelinated, but apparently by glial cells whose somata retained their central position in the nerve. This indicates the presence of oligodendrocytes, but the fate of oligodendrocytes and their contribution to the glial organization and axon regeneration in the lesioned nerve remained unclear.

In the present study oligodendrocytes from the frog CNS were raised in culture to characterize their properties when deprived of axons and during differentiation with a battery of cell- and stage-specific antibodies. Oligodendrocytes resemble Schwann cells in several respects, including their axon growth-supportive properties. With application of the relevant markers to the lesioned optic nerve we have identified elongated glial cells with centroperipheral oriented processes as undifferentiated oligodendrocytes in situ. At early stages of axon regeneration, they are labeled by $\mathrm{O} 4$ antibody but do not express advanced oligodendrocyte/myelin-specific molecules. At later stages, however, advanced oligodendrocyte/myelin markers re-appear in association with the regenerated axons in the peripheral portion of the optic nerve, indicating that frog optic nerve oligodendrocytes differentiate to remyelinate the axons. They are thus able to adapt to the state of the retinal axons. These changes were not observed in the case of oligodendrocytes in the spinal cord, where axon regeneration does not occur (Beattie et al., 1990; Forehand and Farel, 1982; Lang et al., 1995).

\section{MATERIALS AND METHODS Surgery}

Xenopus laevis tadpoles and frogs were bred and raised at the animal research unit of the University of Konstanz. All surgery was in compliance with animal welfare legislation. Prior to operations, young frogs (6 months old) were anesthetized in MS 222 (Sigma) and kept on ice for the duration of the surgical procedure to minimize bleeding. For optic nerve transections, the optic nerve was approached through a small incision in the roof of the mouth, the surrounding muscle tissue and blood vessels were gently teased away, and the nerve was cut with iridectomy scissors. Care was taken not to injure the blood vessels supplying the retina. The spinal cord was transected in frogs ( 6 months old) by exposing the vertebral column between vertebrae 3 and 4 and suturing the wound.

\section{Glial Cell Cultures}

Glial cell cultures were obtained from optic nerves, spinal cord, or sciatic nerves of tadpoles (stage 51-60; Niewkoop and Faber, 1956) or 6 month old frogs. In a few animals, a conditioning lesion was made in the optic nerve 2 weeks prior to preparation of the glia cultures (Agranoff et al., 1967). The glial cells obtained from lesioned optic nerves closely resembled those of normal nerves. No difference was found between glial cells obtained from frogs or tadpoles. In frogs, axons were already myelinated (Lang et al., 1995; Maier and Miller, 1995), whereas most of those in tadpoles were not.

The animals were terminally anesthetized with an overdose of MS 222. Optic nerves, spinal cord, and sciatic nerves were dissected in sterile Leibovitz medium (L15, Gibco). Care was taken to remove connective tissue and meninges. The nerves and cord were cut into small fragments on a Mcllwain tissue chopper, transferred to L15 containing $20 \%$ fetal calf serum (FCS), and allowed to settle. The supernatant was discarded. Nerve fragments were then taken up in culture medium, consisting of DMEM/F12 (1:1, Gibco) supplemented with $5 \%$ FCS, $0.4 \%$ methyl cellulose, $15 \mathrm{mM}$ $\mathrm{HEPES}, 50 \mu \mathrm{g} / \mathrm{ml}$ transferrin, $5 \mu \mathrm{g} / \mathrm{ml}$ bovine insulin, $100 \mu \mathrm{M}$ putrescine, $30 \mathrm{nM}$ sodium selenite, $20 \mathrm{nM}$ progesterone (all from Sigma), and $50 \mu \mathrm{g} / \mathrm{ml}$ gentamycin (Gibco). The nerve fragments were placed on polylysine/ laminin-coated glass coverslips $(500 \mu \mathrm{l}$ suspension/coverslip) and held in place by a second, uncoated coverslip, separated from the tissue by stainless steel spacers. The sandwich cultures were kept in plastic Petri dishes in a humidified chamber at $22^{\circ} \mathrm{C}$ in an incubator. Glia cells emigrate from these fragments and multiply. The culture medium was partially exchanged every $3-4 \mathrm{~d}$, and cultures were maintained over several weeks.

Retinoic acid, thyroid hormone (T3), or forskolin (all from Sigma) were added to cultures at concentrations of $1-10 \mu \mathrm{M}, 3-30 \mathrm{nM}$, and $10-100 \mu \mathrm{M}$, respectively, to determine their influence on glial cell differentiation. 
The cells were grown in the presence of these agents for at least $7 \mathrm{~d}$. Some cultures were analyzed between 2 and $7 \mathrm{~d}$ after forskolin was withdrawn from the medium.

CNS- and PNS-derived glial cells were grown in the presence of $10 \mu \mathrm{M}$ bromodeoxyuridine (BrdU) for $72 \mathrm{~h}$ (Nowakowski et al., 1983) and then fixed and processed for immunocytochemistry as described below. This duration of BrdU treatment allows us to gain an impression of the rate of divisions of precursors (which was high) and, more importantly, also allowed us to show the absence of BrdU incorporation from differentiating (round) oligodendrocytes.

\section{Axon Outgrowth Assay on Glial Cells}

Optic nerve, spinal cord, or sciatic nerve explants (prepared as above) were distributed over polylysinecoated 96-well dishes (Nunc). After $7 \mathrm{~d}$ in culture, the dishes were shaken vigorously for $2 \mathrm{~min}$ and rinsed twice with DMEM/F12 medium. The original explants were dislodged, leaving behind glial cells that had emigrated from the explants. Low-density glial cell carpets were thus obtained, which facilitated counting of axons in coculture assays.

Retinal explants were prepared from tadpoles and frogs that had not received a conditioning lesion of their optic nerves. Retinae were isolated in L15, freed of the pigment epithelium, and flattened with suction on nylon filters. The retinae were cut into squares of $200 \times 200 \mu \mathrm{m}$, rinsed twice in $\mathrm{L} 15$ containing $20 \%$ FCS, and resuspended in DMEM/F12 culture medium with the above supplements. Retinal explants were added to the wells containing the glial cells or, in control experiments, placed into polylysine-coated wells without cells. These cultures were kept for $48 \mathrm{~h}$ at $22^{\circ} \mathrm{C}$ and fixed in $5 \%$ glutaraldehyde in 0.1 phosphate buffer. The number of axons that had emerged from each retinal explant were counted using phase contrast optics (Lang et al., 1995).

\section{Immunostaining of Glial Cells}

Glial cells were subjected to immunostaining procedures as described previously for mammalian or fish glial cells (Bastmeyer et al., 1991; 1994). Monoclonal antibodies (MAbs) A2B5 recognizing O-2A progenitor cells in mammals (Raff et al., 1983; Raff and Miller, 1984; dilution 1:2), 6D2 against fish myelin proteins IP1/IP2 (Jeserich and Waehneldt, 1986; Jeserich and Rauen, 1990; dilution 1:5), 192-IgG against the lowaffinity nerve growth factor (NGF) receptor (gift of $D$. Lindholm; dilution 1:2), O4 as well as O1 (Sommer and Schachner, 1981; dilution 1:5), and anti-galactocerebroside (GalC; Ranscht et al., 1982; dilution 1:20) were applied to live cells. Fixed cells were exposed to MAbs against the peripheral myelin protein Po (gift of J. Archelos; dilution 1:500), the frog-specific myelin marker
"Olig"-antigen (Steen et al., 1989; dilution 1:10), glial fibrillary acidic protein (GFAP; clone G-A-5; Debus et al., 1983; dilution 1:500) and to phosphorylated neurofilaments (SMI-31; Sternberger-Meyer Immunochemicals; dilution 1:500). Fixed cells were also exposed to MAb HNK-1/L2 (Keilhauer et al., 1985; dilution 1:10) and $\mathrm{MAb} 6 \mathrm{C} 2$ against myelin basic protein (MBP; gift of C. Linington; dilution 1:5) to rabbit antisera against fibronectin (FN; Telios; dilution 1:500), the myelin-associated glycoprotein (MAG; provided by M. Schachner; dilution 1:200), proteolipid protein (PLP; gift of C. Linington; dilution 1:400), the astrocyte and Schwann cell marker protein S-100 (Dakopatts; dilution 1:100), and to an antiserum against the cell adhesion molecule L1 (gift of F. Rathjen; dilution 1:1000). The specificity of antibodies against the mammalian myelin proteins MBP, PLP, MAG, and Po and as well as MAb 6D2 against the fish myelin proteins IP1 and IP2, was tested on immunoblots with Xenopus CNS- and PNS-derived myelin and on tissue sections through the Xenopus nervous system (Lang et al., 1995). All substances except $6 D 2$ against IP1 and IP2 (see Results) recognized proteins of the appropriate sizes and selectively stained myelin of the CNS and PNS, respectively.

Cells were fixed in methanol $\left(5 \mathrm{~min},-20^{\circ} \mathrm{C}\right)$ and $4 \%$ paraformaldehyde (PFA) in phosphate-buffered saline (PBS) containing $10 \%$ sucrose, rinsed in PBS $(3 \times 5$ min), and incubated with the primary antibodies [diluted in PBS containing $1 \%$ bovine serum albumin (BSA)] in a humidified chamber $\left(2 \mathrm{~h} ; 37^{\circ} \mathrm{C}\right)$. Secondary antibodies were goat anti-mouse conjugated with tetramethylrhodamine isothiocyanate (TRITC) for fluorescein (FITC; dilution 1:200), donkey anti-rat-carboxymethylindocyanine (Cy-3; preadsorbed against mouse proteins; dilution $1 ; 1,000$ ), or goat anti-rabbit-TRITC or FITC (dilution 1:200; all from Dianova), which were used in suitable combinations for double immunofluorescence. The cultures were rinsed ( $3 \times$ in PBS), incubated briefly ( $5 \mathrm{~min}$ ) with $0.5 \mu \mathrm{g} / \mathrm{ml}$ diamidinophenylindole (DAPI; Sigma) in PBS to visualize cell nuclei, rinsed in PBS, and mounted in Mowiol (Hoechst), containing n-propylgalate (Sigma) as an anti-fading agent. For staining of living glial cells, the cultures were incubated with the relevant antibodies diluted in L15 for $1 \mathrm{~h}$ at $4^{\circ} \mathrm{C}$ prior to fixation and exposure to secondary antibodies.

In some cases the Vectastain ABC kit (Vector Laboratories) was employed to detect immunoreactivity. Immunostaining was performed according to the manufacturer's instructions. To block non-specific antibody binding, the fixed glial cultures were incubated in $5 \%$ normal serum in PBS prior to addition of primary antibodies. In controls, primary antibodies were omitted. Staining was visualized using a Vector aminoethylcarbazole (AEC) substrate kit.

BrdU-treated glial cultures were subjected to a staining procedure allowing the simultaneous visualizing of $\mathrm{O} 4$ and BrdU immunoreactivity (Bastmeyer et al., 1994; Nowakowski et al., 1989). After treatment of live cells 

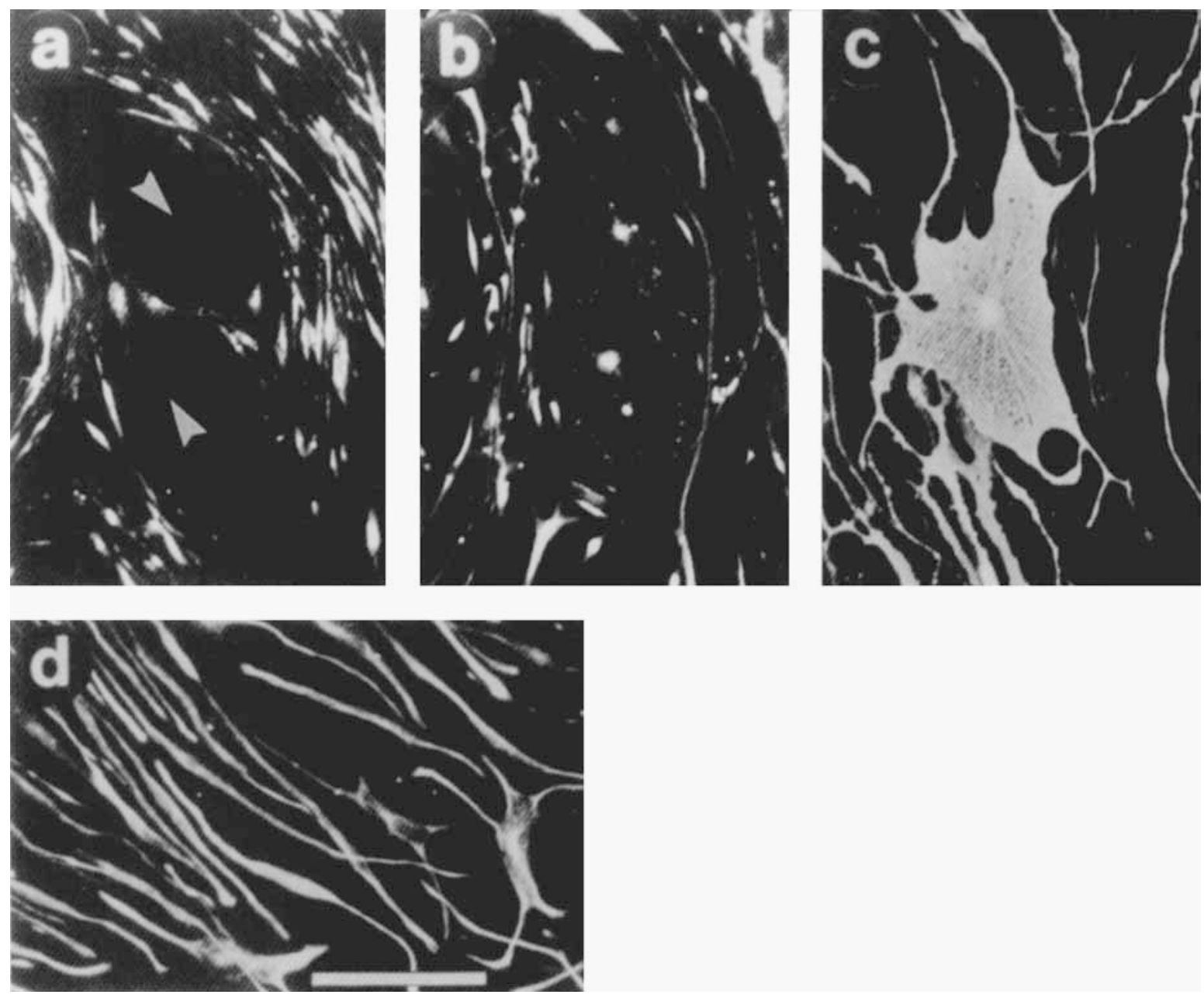

Fig. 1. In vitro characterization of Xenopus glial cells derived from optic nerve and spinal cord. a:MAb 6D2 labels elongated undifferentiated oligodendrocytes but not the round differentiated oligodendrocytes (arrowheads). b: The elongated undifferentiated cells (in contrast to their round and differentiated counterparts in the center) are $\mathrm{S}$ -

with $\mathrm{MAb} \mathrm{O} 4$ (IgM), cultures were fixed in methanol and $4 \%$ PFA, washed in PBS, and incubated in goat antimouse-FITC secondary antibodies. After postfixation (2 $\mathrm{min}$ ) in PFA, the cultures were exposed to $2 \mathrm{~N} \mathrm{HCl}$ (10 $\mathrm{min}$ ) and rinsed repeatedly in $100 \mathrm{mM}$ borate buffer and PBS containing 1\% BSA and $0.025 \%$ Triton X-100. $\mathrm{MAb}$ against BrdU (IgG; Becton-Dickinson) was added to the cultures at a dilution of 1:100 in PBS/BSA/Triton $\mathrm{X}-100\left(2 \mathrm{~h} ; 37^{\circ} \mathrm{C}\right)$, which were then exposed to a TRITCconjugated IgG-specific goat anti-mouse antibody (1:200; Dianova) for $2 \mathrm{~h}$ at $37^{\circ} \mathrm{C}$. Cultures were counterstained with DAPI and mounted as described above.

\section{Immunostaining of Cryosections}

Normal and transected optic nerves were immersed in TissueTek (Miles Inc.) and frozen in liquid nitrogen. Cryostat sections $(10 \mu \mathrm{m})$ were air dried for $1-2 \mathrm{~h}$ on
100 positive. c: The elongated undifferentiated cells and the round and spread-out differentiated oligodendrocytes are both stained by O4. d: Elongated undifferentiated and differentiated oligodendrocytes (see Fig. 4) express GFAP. Scale bar $=100 \mu \mathrm{m}$.

Vectabond-treated slides (Vector Laboratories). For immunohistochemical detection of myelin proteins (with antibodies to MAG, MBP, PLP, and "Olig"-antigen) sections were fixed in Clark's solution (95\% ethanol, $5 \%$ acetic acid) for $25 \mathrm{~min}$ at $4^{\circ} \mathrm{C}$. Sections to be stained with MAbs O4, O1, and anti-GalC were fixed in methanol $\left(-20^{\circ} \mathrm{C}\right)$ over $1 \mathrm{~min}$. Those to be stained with anti FN, GFAP, S-100, and SMI-31 were fixed for $5 \mathrm{~min}$.

To prevent nonspecific binding, sections were blocked for $30 \mathrm{~min}$ with $\mathrm{PBS}$ containing $1 \% \mathrm{BSA}$. Incubation with primary antibodies was for $2 \mathrm{~h}$ at $37^{\circ} \mathrm{C}$ or overnight at $4^{\circ} \mathrm{C}$ as described above. Secondary antibodies were Cy-3-conjugated donkey anti-mouse IgG or IgM, donkey anti-rat, or donkey anti-rabbit (all from Dianova) to which sections were exposed for $2 \mathrm{~h}\left(37^{\circ} \mathrm{C}\right)$ at a dilution of 1:1,000. Sections were counterstained with DAPI and coverslipped under Mowiol containing n-propylgalate.

In some cases, cryosections were processed for immu- 

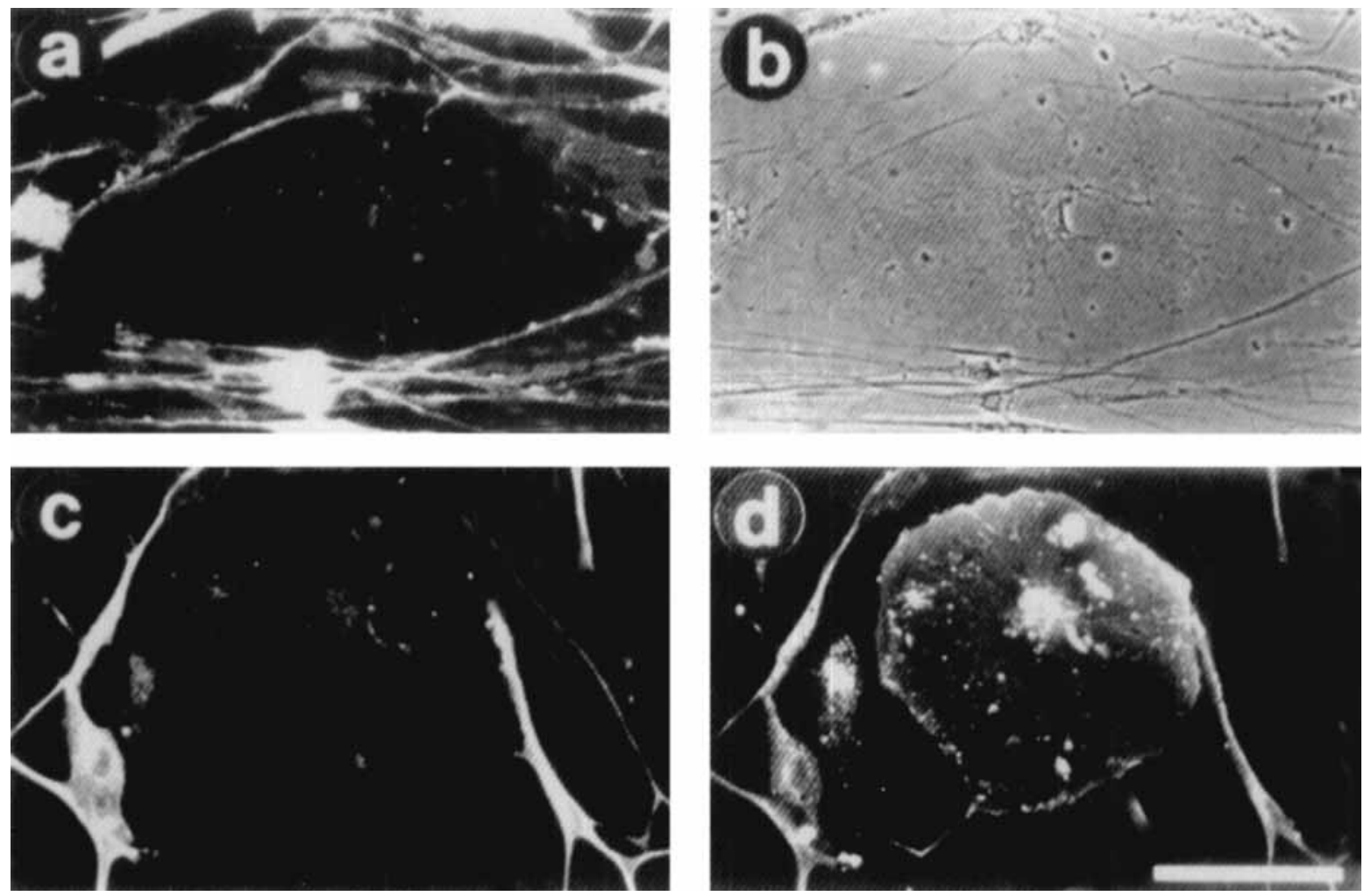

Fig. 2. Elongated undifferentiated oligodendrocytes (b, phase contrast) are labeled by the HNK-1 antibody (a), carry the cell adhesion molecule L1 (e), and are O4 positive (d). O4-positive differentiated oligodendrocytes are HNK-1 and L1 negative (a,c). Scale bar $=100 \mu \mathrm{m}$.
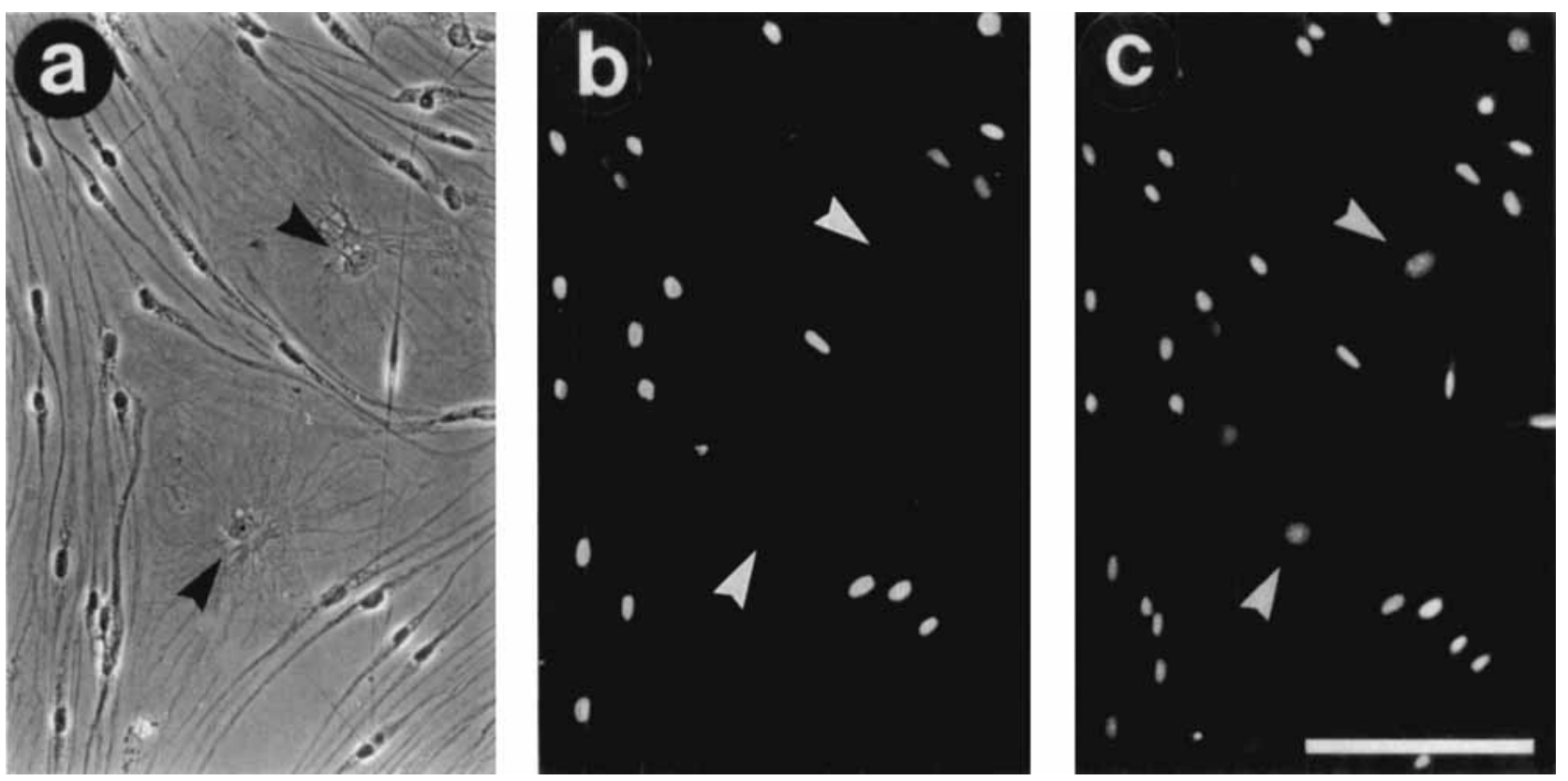

Fig. 3. Undifferentiated oligodendrocytes (phase contrast in a) incorporate $\operatorname{BrDU}$ (b), but highly branched oligodendrocytes (a), whose DAPI labeled nuclei are marked by arrowheads (a, b, and c) do not. Scale bar $=100 \mu \mathrm{m}$. 

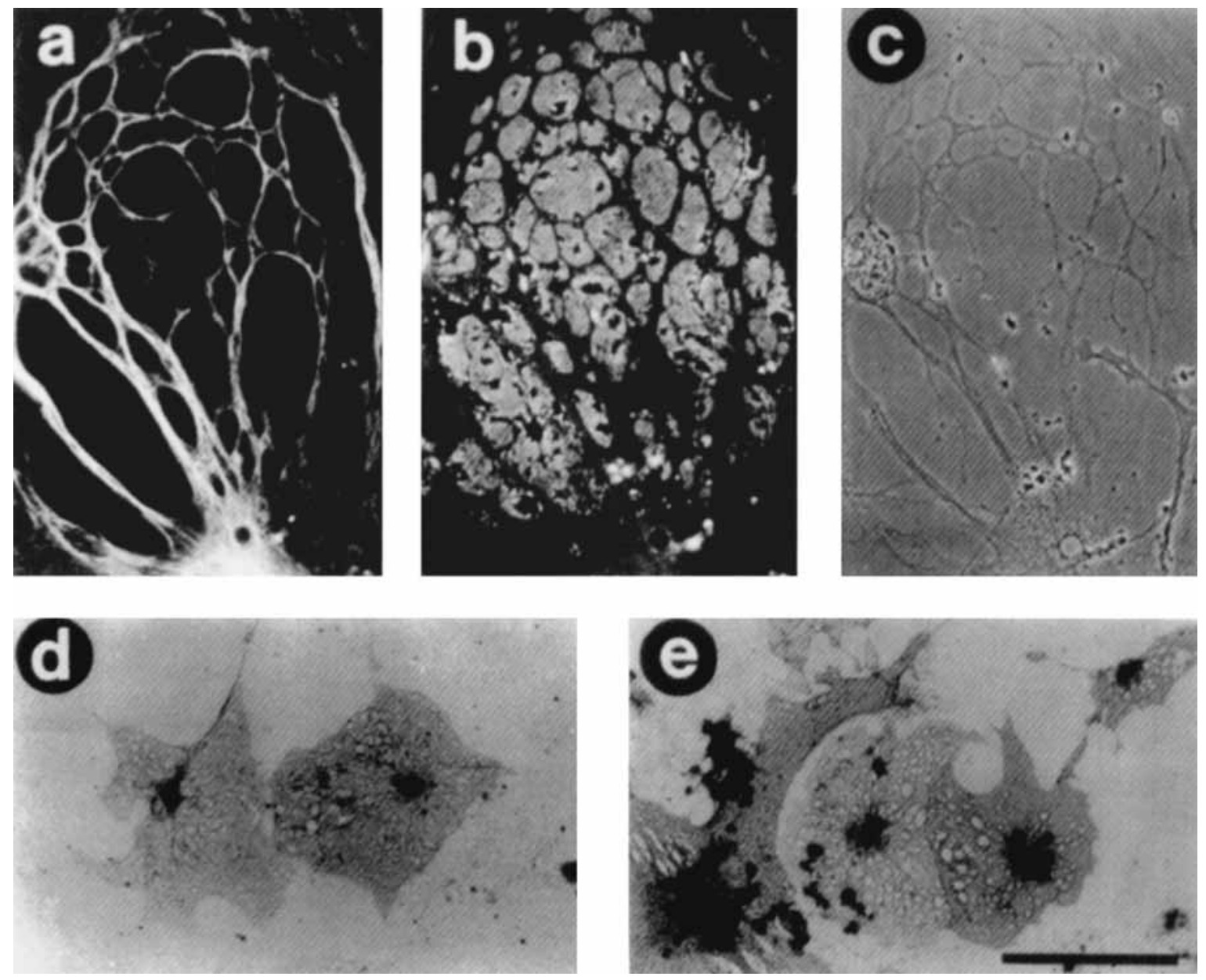

Fig. 4. Highly branched oligodendrocytes (phase contrast in c) express GFAP (a) and MBP (b) in their membrane sheets between the GFAP-positive veins. Scale bars $=50 \mu \mathrm{m}$. Anti-MAG (d) and antiPLP (e) immunoreactivities of differentiated oligodendrocytes are visualized by the vectastain $A B C$ kit. The densely stained irregular structures represent PLP-labeled myelin debris. Scale bar $=200 \mu \mathrm{m}$.

nostaining according to the Vectastain $A B C$ standard protocol. Immunoreactivity was visualized using a Vector diaminobenzidine (DAB) substrate kit.

\section{RESULTS \\ Characterization of Undifferenentiated and Differentiating Xenopus Oligodendrocytes In Vitro}

To identify oligodendrocytes at various stages of differentiation after lesioning of the optic nerve and spinal cord, and to evaluate their properties, they were first characterized in vitro. Whether derived from already myelinated tracts of frogs or from tracts of tadpoles at premyelination stages (Lang et al., 1995; Maier and Miller, 1995), glial cultures from optic nerves and spinal cord at $14 \mathrm{~d}$ in vitro contained predominantly undifferentiated oligodendrocytes and a few differentiating oligodendrocytes interspersed between them. GFAP- positive astrocytes, which were negative for oligodendrocyte/myelin-specific markers, formed clusters and eventually detached from the substrate.

Undifferentiated oligodendrocytes exhibited an elongated bipolar shape reminiscent of axon-deprived Schwann cells. They were $\mathrm{O} 4$ positive and contained GFAP-positive fibrils (Fig. 1) but did not express O1/ Gal-C, which was, however, present on round differenitating oligodendrocytes (Lang et al., 1995). They shared further molecular components with Schwann cells (see Fig. 5), which were lost on differentiation. These were S-100 protein (Fig. 1) (Mirsky and Jessen, 1990), the HNK-1/L2 epitope, the cell adhesion molecule L1 (Fig. 2) (Keilhauer et al., 1985; Künemund et al., 1988), and a protein recognized by MAb 6D2 (Fig. 1), which differs from the fish myelin proteins IP1/IP2 of 27 and $29 \mathrm{kd}$, respectively (Jeserich and Waehneldt, 1986; Jeserich and Rauen, 1990), against which 6D2 was made. In immunoblots with Xenopus myelin 6D2 recognized a band of approximately $100 \mathrm{kd}$. The identity of this frog 

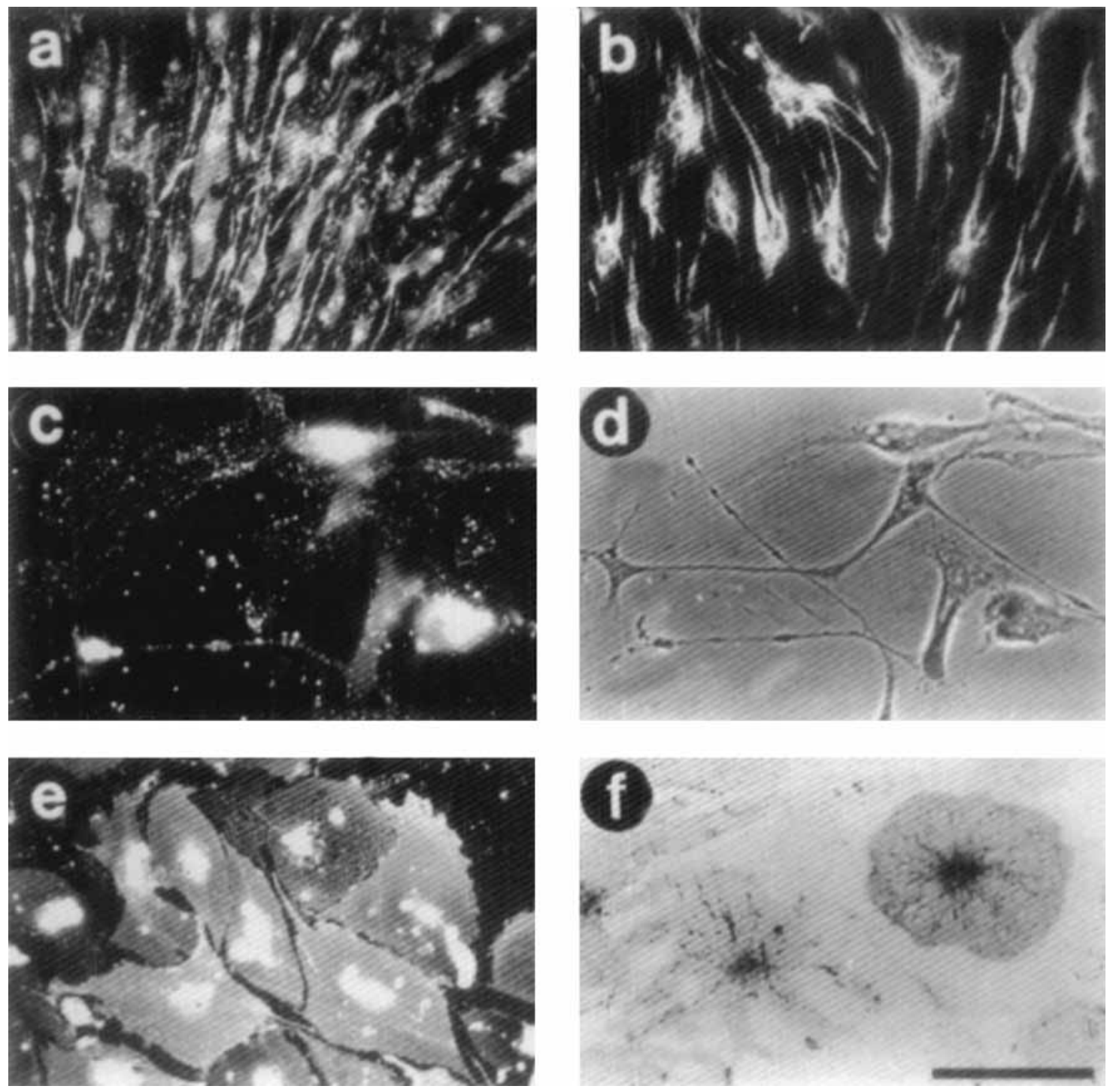

Fig. 5 Xenopus Schwann cells are labeled by O4 (a) and express GFAP (b) and low-affinity NGF receptor (c, shown by the typical punctate staining). Phase contrast (d) of (c). After exposure to forskolin, Schwann cells acquire a morphology reminiscent of oligodendrocytes and express Gai-C (e) and Po (f, demonstrated by the Vectastain ABC kit). Scale bar $=200 \mu \mathrm{m}$.

myelin protein is presently unknown but is of interest since it appears to be developmentally regulated. In contrast to mammalian glia precursors of the $\mathrm{O}_{2} \mathrm{~A}$ lineage (Raff et al., 1983), undifferentiated Xenopus oligodendrocytes were A2B5 negative. While most of the undifferentiated oligodendrocytes incorporated BrdU even after $14 \mathrm{~d}$ in vitro, O1/Gal-C-positive, round oligodendrocytes did not (Fig. 3). During their differentiation into $\mathrm{O} 1 / \mathrm{Gal}$-C-expressing cells, which was induced by forskolin (Lang et al., 1995), oligodendrocytes lost HNK1/L2, L1, and 6D2 immunoreactivity and later acquired the myelin markers characteristic of mature oligodendrocytes-MBP, PLP, MAG (Fig. 4), and the "Olig" antigen (Steen et al., 1989). They retained GFAP (Fig. 4), which is unusual for differentiated oligodendrocytes (Raff et al., 1983). GFAP was restricted to the thickened veins of the cell, while myelin marker proteins were found in the membraneous sheets between them.

Xenopus Schwann cells, being O4 and GFAP positive, also acquired O1/Gal-C (Fig. 5) and MAG on exposure to forskolin (Lemke and Chao, 1988; Morgan et al., 1991) but expressed Po instead of PLP and carried lowaffinity NGF receptors (Fig. 5). This clearly distinguishes Schwann cells from Xenopus oligodendrocytes.

Both undifferentiated Xenopus oligodendrocytes and Schwann cells were able to support axon outgrowth when they were cocultured with retinal explants (Fig. 6). When derived from frogs that had not received a conditioning optic nerve lesion, explants showed little or no outgrowth on polylysine. (Eighteen explants had 0 axons, five had less than 20 , and one explant more than 20 axons.) Substantial outgrowth from retinal ex- 

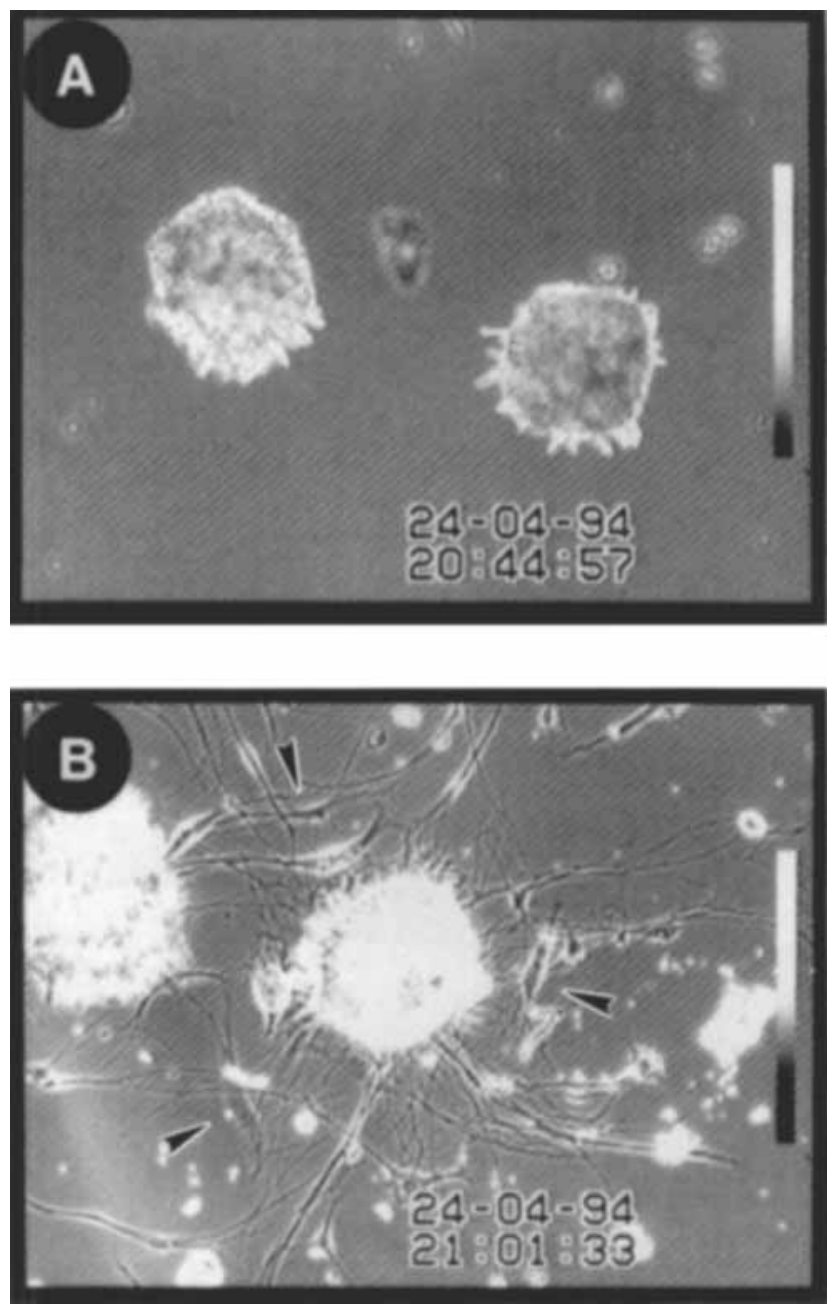

Fig. 6. Retina mini-explants on polylysine (a) after $2 \mathrm{~d}$ in vitro fail to extend axons, but axons do extend (b) in the presence of CNSderived glial precursor cells (arrowheads). Videoprints; vertical bars $100 \mu \mathrm{m}$.

plants is only seen on polylysine when the optic nerve has received a conditioning lesion several days prior to retina explantation (Agranoff et al., 1967). However, when cocultured with Schwann cells or with optic nerveor spinal cord-derived oligodendrocytes, all explants extended axons, and the majority had more than 20 axons. (On glial precursor cells of the CNS, 16 explants of 23 had more than 20 axons. Of 23 explants on sciatic nervederived Schwann cells, 15 gave rise to more than 20 axons). These axons expressed HNK-1 and L1 molecules, which could conceivably participate in axon-glia interactions (Bastmeyer et al., 1993; Keilhauer et al., 1095; Kühnemund et al., 1988).

On forskolin-induced differentiation and the concurrent loss of the developmentally regulated molecules, oligodendrocytes also lost their axon growth-stimulating properties (Lang et al., 1995). Retinoic acid and thyroid hormone (T3) -were ineffective in driving oligodendrocytes maturation. When cultures were subse- quently deprived of forskolin and glial cells left therein for up to $7 \mathrm{~d}$, oligodendrocytes remained in their differentiated state and did not revert to precursor stages. Thus withdrawal of the agent that induced oligodendrocyte differentiation is not sufficient for dedifferentiation.

\section{Xenopus Glial Cells After Lesion of the Optic Nerve and Spinal Cord}

Based on this in vitro characterization glial cell features in optic nerves and spinal cords of normal and lesioned frogs were analyzed. Special attention was paid to the optic nerve because it has been demonstrated that its glial cells undergo marked changes in morphology and spatial arrangement on lesion (Bohn and Reier, 1985; Reier and Webster, 1974).

In normal optic nerves of frogs (Fig. 7), retinal axons identified by the neurofilament marker SMI-31 occupied the entire cross section of the nerve (Reier and Webster, 1974) and were surrounded by structures immunoreactive to $\mathrm{O} 4$, GalC, MBP, PLP, and "Olig" representing myelin sheaths (Lang et al., 1995). GFAP staining was associated with distinct cellular processes lying between the paths of the axons. Glial cell bodies identified by the nuclear stain DAPI were scattered throughout the nerve. This spatial organization of markers indicative of axons, myelin, oligodendrocytes, and astrocytes (Maier and Miller, 1995) was in perfect agreement with an earlier light and electron microscopic description of these nerve components (Reier and Webster, 1974). Optic nerves 2 weeks after lesion were filled with myelin debris that stained with all myelin-specific antibodies including $\mathrm{O} 4$. Therefore, it was difficult to visualize and characterize the O4- and GFAP-positive glial cells with radial processes that had emerged intermittently (see below).

Four weeks after optic nerve transection (Fig. 8), the myelin markers GalC, MBP, PLP, and "Olig" were absent from the nerve (except for minor amounts of debris). This allowed us to recognize the abundance of $\mathrm{O} 4$ and GFAP-positive, radially oriented glia processes that emanated from somata in the center of the optic nerve. Consistent with the report of Reier and Webster (1974), DAPI-labeled glial cell somata were clustered in the center, and glial processes reminiscent of radial glia extended in a centroperipheral orientation. Cells and processes were GFAP positive but in adjacent sections radial processes were intensively stained by $\mathrm{O} 4$. It cannot be determined unequivocally from light microscopal analyses whether both these markers are coexistent in the same cells and processes. Regenerating and SMI31-positive retinal axons were seen in the periphery of the nerve (Bohn and Reier, 1985; Reier and Webster, 1974). The core of the nerve contained hardly any axons, but more glial cell somata than normal nerves. Exposure of sections to antibodies HNK-1/L2, 6D2, anti-L1, and anti-S100 gave a diffuse and homogenous stain 

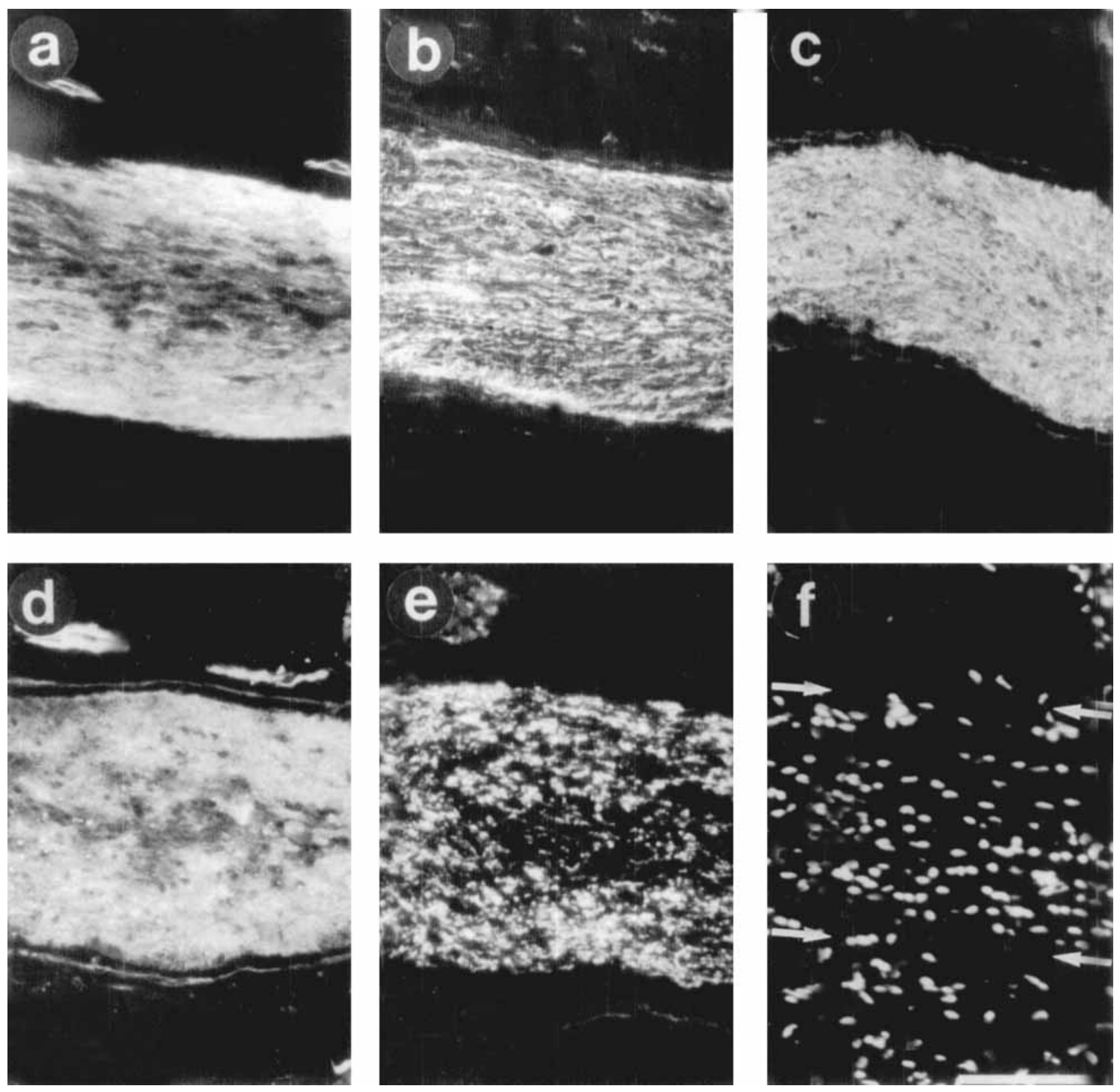

Fig. 7. Consecutive longitudinal sections of a normal Xenopus optic nerve, with retinal axons revealed by the neurofilament marker SMI-35 (a). GFAP-positive glial cell processes are distributed across the nerve (b). The nerve displays the oligodendrocyte/myelin markers O4 (c), Gal-C (d), and PLP (d). Glial cell nuclei revealed by DAPI stain (f) are seen throughout the nerve (whose borders are marked by white arrows) and in neighboring tissue. The retina is to the left. Scale bar $=100 \mu \mathrm{m}$.

across the nerve so that it was not possible to determine whether axons and/or glial cells carried the markers.

Eight weeks after optic nerve section (Fig. 9), when most axons have re-formed connections in the optic tectum (Taylor and Gaze, 1985) and myelin sheets have re-formed (Bohn and Reier, 1985; Reier and Webster, 1974), the myelin markers GalC, MBP, PLP, and "Olig" were present. These markers appeared in the periphery of the nerve in those regions where SMI-31-positive axons were located. No staining was obtained with anti-
Po in the lesioned (or normal) nerve, at either 2, 4, or 8 weeks, indicating that there was no Schwann cell invasion. Most glial cell somata, identified by nuclear DAPI stain, were still at the center of the nerve and were rare in among the axons, the position most common for myelin-forming oligodendrocytes. The nerve core remained mostly free of advanced myelin markers. Radial processes emanating from glial cells that were positive for $\mathrm{O} 4$ and GFAP persisted.

However, when retinal axons were prevented from 

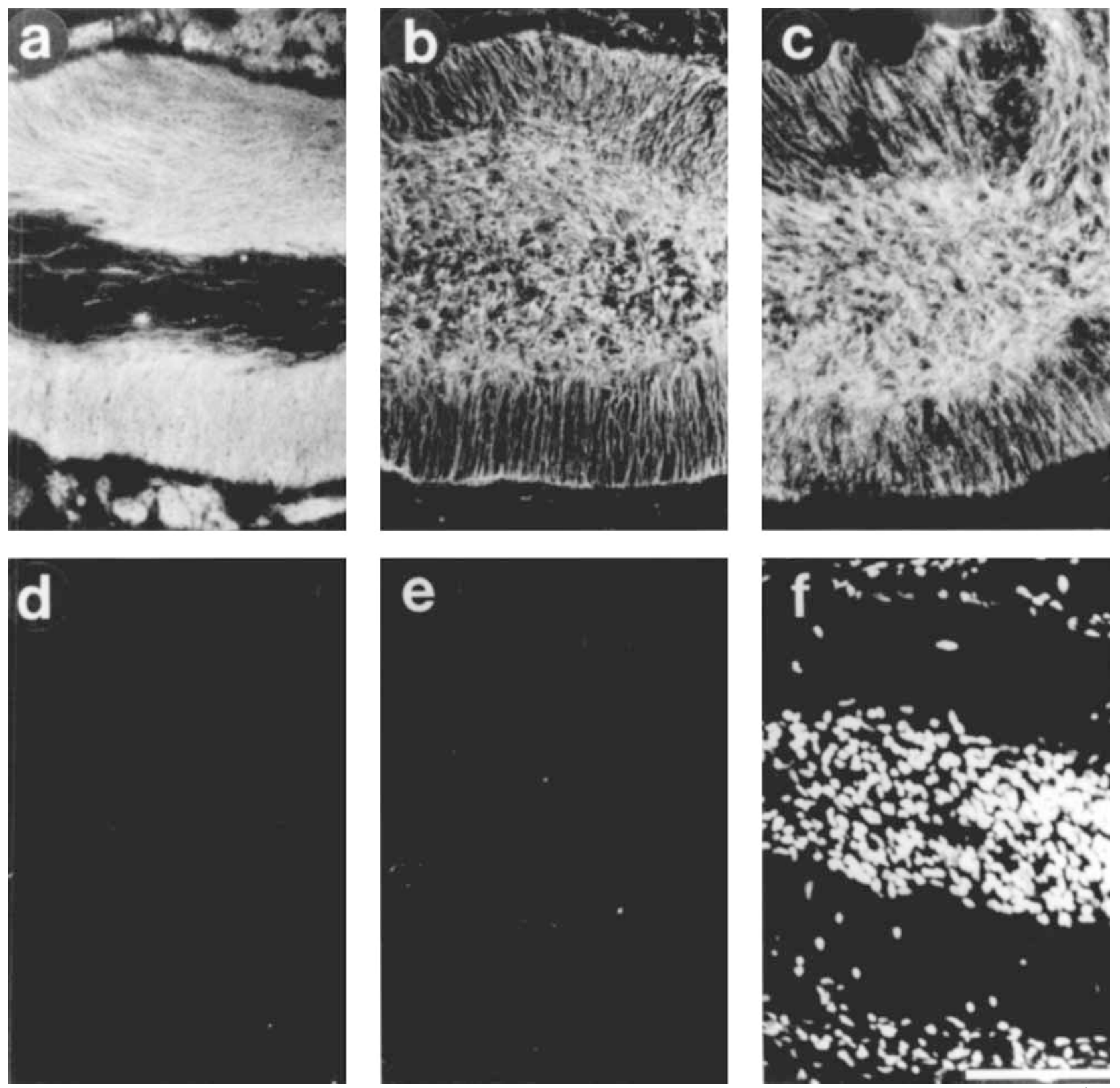

Fig. 8. Consecutive longitudinal sections of the optic nerve 4 weeks after lesion. Regenerating retinal axons labeled by SMI-35 (a) course preferentially in the peripheral portion of the nerve, and only a few pass through its central portion, where glial cell nuclei are clustered (f). Glial cells labeled by GFAP (b) and $\mathrm{O} 4$ (c) form centroperipherally oriented processes in the nerve's peripheral portion. Gal-C (d) and MBP (e) are absent from the nerve at this stage. Nuclear DAPI staining (f) Scale bar $=100 \mu \mathrm{m}$.

invading the nerve (by removal of the eye 8 weeks prior to examination), the distribution of $\mathrm{O} 4$-positive cells in the optic nerve was different from that of GFAP-positive cells, and no advanced oligodendrocyte and myelin marker was present. Moreover, the glial cell somata were not clustered, and centroperipherally oriented processes were not observed (Fig. 10). Thus, the re-organization of glia cells including formation of centroperipheral processes and the acquisition of oligodendrocyte/ myelin-specific markers apparently requires the presence of regenerating retinal axons.
These findings show the loss of advanced myelin markers, probably due to myelin breakdown, phagocytosis, and dedifferentiation or death of mature oligodendrocytes during retinal axon regeneration. They further demonstrate the emergence of O4-positive cells with radially oriented processes that either coexpress GFAP or coexist with morphologically similar cells expressing GFAP. O4-positive glial cells appear to represent undifferentiated oligodendrocytes, which, in the presence of axons, can apparently differentiate to oligodendrocytes expressing advanced myelin markers. 

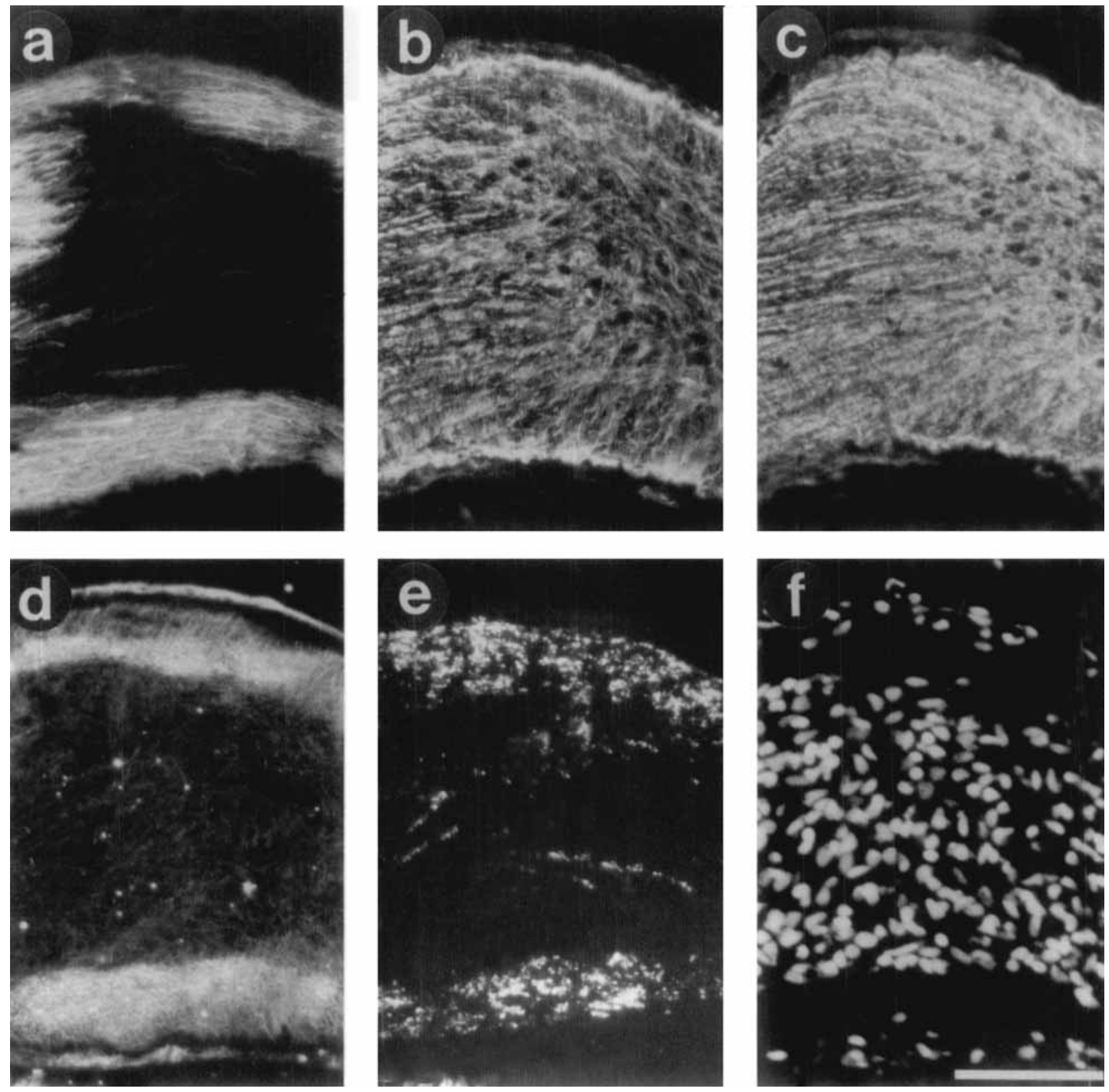

Fig. 9. Consecutive, oblique-longitudinal sections at 8 weeks after lesion. The regenerated axons, identified by SMI-35 (a) remain primarily in the nerve's peripheral portion. Glial cells labeled by GFAP (b) and $\mathrm{O} 4$ (c) persist throughout, and the radial orientation of their processes is visible in the oliquely cut sections. Sections deeper into

the nerve reveal the presence of Gal-C (d) and MBP (e) predominantly in the periphery of the nerve, where most of the regenerated axons are located. DAPI stain (f) of glial nuclei demonstrating their persistence in the nerve's center. Scale bar $=100 \mu \mathrm{m}$

The central position of most glial cell somata and the persistence of O4-positive radial processes suggest that the undifferentiated oligodendrocytes differentiate and express myelin markers where they are in contact with the axons.

No such changes were observed after transection of the spinal cord in frogs, 4 or 8 weeks after lesion. Four weeks after spinal cord transection, the lesion site was readily identified as a cell-free gap between the proximal and distal cord (Fig. 11). Descending axons in the

ventral half of the cord were visualized by SMI-31 and they ended near the lesion site. Myelin around the descending axons (Lang et al., 1995) appeared to persist, as demonstrated by the presence of Gal-C, MBP, "Olig", and PLP in the ventral cord in association with the axons (Fig. 11). O4 staining was co-extensive with these markers. The pattern of GFAP expression was distinct from that of O4 (Maier and Miller, 1995). At the lesion, a narrow rim of GFAP- and fibronectin-positive cells formed at the cut ends of the cord. This occurred at 4 

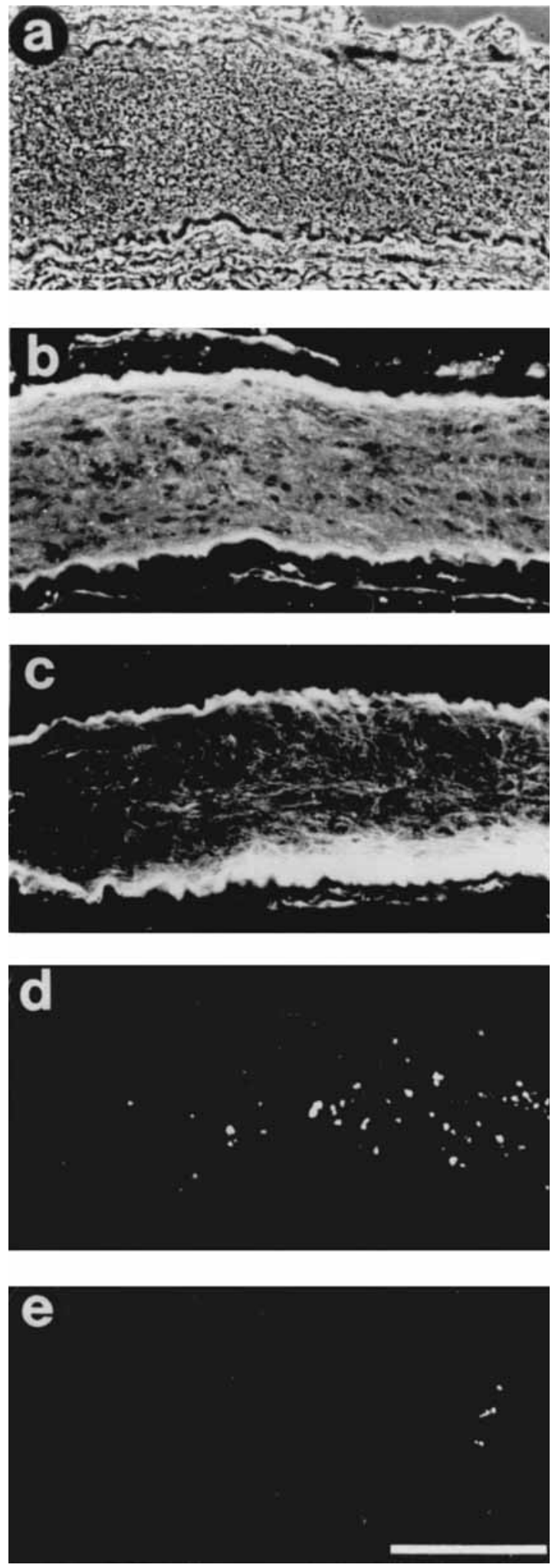

Fig. 10. Longitudinal sections through an optic nerve, 8 weeks after removal of the eye; phase contrast (a) Glia cells labeled by $\mathrm{O} 4$ (b) and GFAP (c) do not exhibit a preferred orientation of their processes, and Gal-C (d) and MBP (e) are absent (except for some Gal-C-positive debris). Scale bar $=100 \mu \mathrm{m}$. weeks and was unchanged 8 weeks after lesion, except that the gap between the cut ends gradually filled up with GFAP- and fibronectin-positive cells. Thus, in the Xenopus spinal cord where lesioned axons fail to regenerate (Beattie et al., 1990; Forehand and Farel, 1982; Lang et al., 1995), myelin markers in the vicinity of the cut axons persist. O4-expressing glia precursors and radial processes, both of which are present in the optic nerve, are not seen at the lesion or elsewhere in the cord.

\section{DISCUSSION}

This study provides evidence for an abundance of undifferentiated oligodendrocytes during retinal axon regeneration following optic nerve transection in frogs. The in vitro and in vivo behavior of these cells suggests that Xenopus glial cells of the oligodendrocyte lineage are highly susceptible to the absence, presence, and regenerative state of the retinal axons and are induced to differentiate into cells that express myelin markers. This adaptive plasticity may be advantageous for CNS fiber tract repair. Indirect evidence in support of this view is the persistence of myelin markers and absence of abundant undifferentiated oligodendrocytes after lesion in the spinal cord where axons fail to regenerate (Beattie et al., 1990; Lang et al., 1995).

The in vitro properties of Xenopus oligodendrocytes show their ability to respond to deprivation of axons. Their phenotype in culture is that of undifferentiated cells that divide over weeks. This sets them apart from mammalian oligodendrocytes (Raff and Miller, 1984), which otherwise have many of the same myelin marker molecules (Pfeiffer et al., 1993). In this adaptive plasticity, Xenopus oligodendrocytes resemble Schwann cells (Bunge, 1993), although they differ in other respects (Lemke and Chao, 1988; Morgan et al., 1991). However, both undifferentiated oligodendrocytes and Schwann cells continue to divide in culture, transiently express similar molecules, support axonal growth, and require external cues to differentiate. Related characteristics have been found in goldfish oligodendrocytes (Bastmeyer et al., 1993, 1994; Jeserich and Rauen, 1990) and may be helpful or prerequisitory for axon regeneration and subsequent remyelination.

These properties were similar whether oligodendrocytes in culture were derived from the Xenopus optic nerve or spinal cord, and whether oligodendrocytes had been engaged in axon myelination or not. Those obtained from frogs must be derived from dedifferentiating oligodendrocytes or from in vivo resident precursors, but which of these alternatives applies is unknown. Likewise, available data do not allow us to decide whether individual oligodendrocytes that were engaged in myelination dedifferentiate on lesioning of the optic nerve and redifferentiate to remyelinating cells. However, cells of the oligodendrocyte lineage of both sources, optic nerve and spinal cord, apparently possess the ability to adapt to lesions in the system of origin, as evidenced by their in vitro properties. Only in the optic 

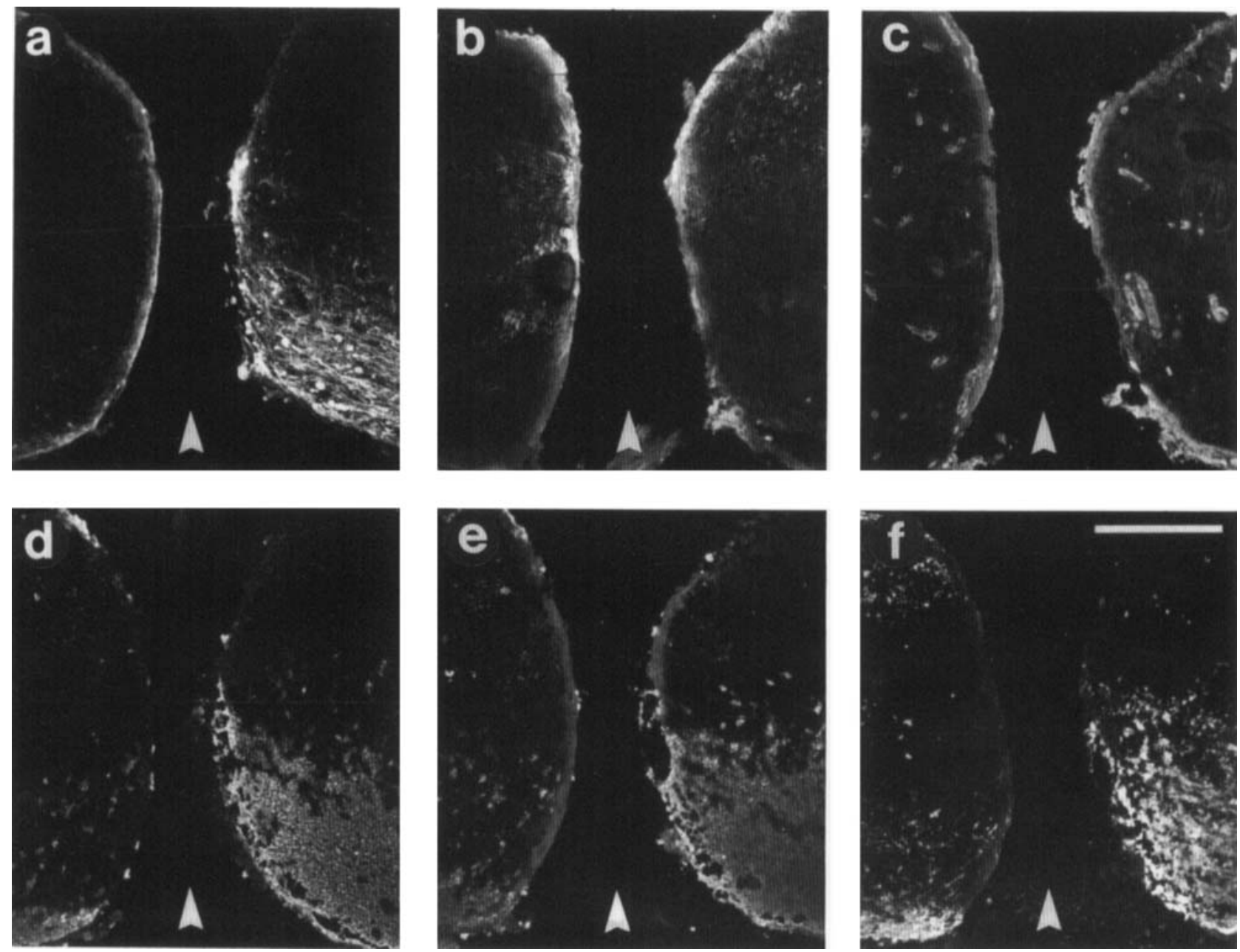

Fig. 11. Consecutive longitudinal sections through the spinal cord 4 weeks after spinal cord transection. The gap between the proximal (right) and distal (left) cord is indicated by an arrowhead. Descending axons (a) labeled by SMI-35 fail to cross the gap. Anti-GFAP (b) and -fibronectin (c) positivity is seen in a narrow zone bordering the cut cord. Myelin markers O4 (d), Gal-C (e), and MBP (f) are present mainly in the proximal stump of the cord and predominantly in those regions where large numbers of myelinated axons are present. Scale bar $=200 \mu \mathrm{m}$ nerve do they display the lesion-induced repair response. That regenerating retinal axons indeed become remyelinated by oligodendrocytes was known from previous investigations (Bohn and Reier, 1983; Reier and Webster, 1974), but their intermittent fate after optic nerve lesion and during axon re-elongation was unresolved. Our present data reveals an abundance of $\mathrm{O} 4-$ positive undifferentiated oligodendrocytes in the regenerating optic nerve. These cells are present during axon regeneration and are apparently in among the pool of glia cells that display the unusual spatial organization so typical of and unique to the Xenopus injured optic nerve (Bohn and Reier, 1983; Reier and Webster, 1974). Whether these 04-positive cells support axon regrowth as do their presumed counterparts in vitro cannot be determined at present. However, that they are responsive to the presence and regenerative state of the axons and therefore are susceptible to cues from their environment is suggested by two further results. First, the rearrangement of optic nerve glia was not observed after eye removal, which deprives the nerve of axons. Second, we found expression of advanced myelin markers in the peripheral portion of the optic nerve where elongated processes of the glial cells are near regenerating retinal axons. This speaks for the view that O4positive oligodendrocyte precursor-like cells are induced to express advanced myelin markers (for axon remyelination) through sustained contact with regenerating axons, which meanwhile have re-formed connections with their targets (Taylor and Gaze, 1985). In their dependence on axons, oligodendrocytes in vivo resemble O4 oligodendrocyte precursors in vitro, which require specific stimuli for expression of advanced myelin markers like Schwann cells (Bunge, 1993) and fish oligodendrocytes (Bastmeyer et al., 1994).

In contrast to the latter, most Xenopus glial cells producing myelin marker molecules and enwrapping axons apparently retain their somata in the optic nerve's center, instead of moving into the axon territories. This is deduced from DAPI-labelled nuclei found predomi- 
nantly in the center of the nerve rather than among the axons, and by related observations of Reier and Webster (1974), who identified oligodendrocyte somata ultrastructurally within the centrally located pool of glia. This configuration in turn implies that myelinforming cells may reach the axons by means of their elongated processes and express myelin markers locally in these peripheral structures. This would resolve the question of where the oligodendrocytes remained and how they gained access to the axons.

Because of their morphology and content of fibrils most of the glial cells with long processes were thought to be astrocytes (Reier and Webster, 1974). Our data show that GFAP-positive and O4-positive cells and processes occur in the very same spatiotemporal pattern. Hence, both markers may coexist within one cell, as was in fact observed in vitro. However, Reier and Webster (1974) also reported other features specific to astrocytes, such as desmosomes, glial cell processes partitioning bundles of axons, and the presence of a glia limitans. Thus, astrocytes are definitely present along with oligodendrocytic cells. In culture, both macroglial types can be distinguished since astrocytes are GFAP positive but negative for $\mathrm{O} 4$ and all oligodendrocyte specific markers. They are also distinguishable in the normal optic nerve and in the spinal cord (Maier and Miller, 1995). However, since oligodendrocytes possess GFAP in addition to $\mathrm{O} 4$ and advanced myelin markers, we cannot discern the in vivo astrocytes with the present set of markers. This in turn implies, however, that the lesion-induced glia reorganization extends to astrocytic cells as well.

That both types of glia respond quite differently to fiber tract lesions in other parts of the Xenopus CNS is demostrated in the case of the spinal cord. The distribution of cellular markers indicative of axons, oligodendrocytes, fibronectin, and GFAP in the lesioned spinal cord is consistent with the view that myelin around the proximal portion of axons persists, that axons fail to regrow (Beattie et al., 1990; Lang et al., 1995), and that a sort of glial scar made up of astrocytic and mesenchymal cells (Reier and Houlé, 1988) develops near the lesion. No signs of oligodendrocyte dedifferentiation were noted. This contrasts with the apparent ability of these glial cells to display the phenotype of undifferentiated oligodendrocytes in vitro. This finding means that in vivo conditions prevent their change.

Whether the failure of axon regeneration-due to the presence of neurite growth inhibitors associated with spinal cord oligodendrocytes (Lang et al., 1995) - is the primary cause for the absence of oligodendrocyte changes or whether other signals participate in these events remains to be explored.

\section{ACKNOWLEDGMENTS}

This work was supported by the Gemeinnützige Hertiestiftung and the Deutsche Forschungsgemeinschaft (DFG, Stu 112/10-2) and by a stipend of the Boehringer
Ingelheim Fonds to D.M.L. We thank Mary Anne Cahill for correcting the English.

\section{REFERENCES}

Agranoff, B.W., Field, P., and Gaze, R.M. (1967) Neurite outgrowth from explanted Xenopus retina: An effect of prior optic nerve section. Brain Res., 113:225-234.

Ankerhold, R., Kaethner, R.J., and Stuermer, C.A.O. (1995) Morphology of oligodendrocytes in the goldfish optic tract and their fate after optic nerve transection. Soc. Neurosci. Abstr., 20:42

Bastmeyer, M., Beckmann, M., Schwab, M.E., and Stuermer, C.A.O. (1991) Growth of regenerating goldfish axons is inhibited by rat oligodendrocytes and CNS myelin but not by goldfish optic nerve tract oligodendrocyte-like cells and fish CNS myelin. J. Neurosci. 11:626-640.

Bastmeyer, M., Bähr, M, and Stuermer, C.A.O. (1993) Fish optic nerve oligodendrocytes support axonal regeneration of fish and mammalian retinal ganglion cells. Glia, 8:1-12.

Bastmeyer, M., Jeserich, G., and Stuermer, C.A.O. (1994) Similarities and differences between fish oligodendrocytes and Schwann cells in vitro. Glia, 11:300-314.

Beattie, M.S., Bresnahan, J.C., and Lopate, G. (1990) Metamorphosis alters the response to spinal cord transection in Xenopus laevis frogs. J. Neurobiol., 21:1108-1122.

Bohn R.C. and Reier, P.J. (1985) Retrograde degeneration of myelinated axons and reorganization in the optic nerves of adult frogs (Xenopus laevis) following nerve injury or tectal ablation. J. Neurocytol, $14: 221-244$

Bunge, R.P. (1993) Expanding roles for the Schwann cell: Ensheathment, myelination, trophism and regeneration. Curr. Opin. Neurobiol. 3:805-809.

Bunge, R.P. and Hopkins, J.M. (1990) The role of peripheral and central neuroglia in neural regeneration in vertebrates. Semin. Neurosci., 2:509-518.

Debus, E., Weber, K., and Osborn, M. (1983) Monoclonal antibodies specific for glial fibrillary acidic (GFA) protein and for each of the neurofilament triplet polypeptides. Differentiation, 25:193 203

Forehand, C.J. and Farel, P.B. (1982) Anatomical and behavioral recovery from the effects of spinal cord transection: Dependence on metamorphosis in anuran larvae. J. Neurosci, 2:654-662.

Gaze, R.M. (1970) Formation of Nerve Connections. Academic Press, London.

Jeserich, G. and Rauen. T. (1990) Cell cultures enriched in oligodendrocytes from the central nervous system of trout in terms of phenotypic expression exhibit parallels with cultured rat Schwann cells. Glia, 3:65-74.

Jeserich, G. and Waehneldt, T.V. (1986) Characterization of antibodies against major fish CNS myelin proteins: Immunoblot analysis and immunohistochemical localization of $36 \mathrm{~K}$ and IP2 proteins in trout nerve tissue. J. Neurosci. Res., 15:147-158.

Keilhauer, G., Faissner, A., and Schachner, M. (1985) Differential inhibition of neurone-neurone, neurone-astrocyte and astrocyteastrocyte adhesion by L1, L2, and N-CAM antibodies. Nature, 316:728-730.

Kollros, J.J. (1961) Mechanisms of amphibian metamorphisis: Hormones, Am. Zool, 1:107-114.

Kollros, J.J. (1981) Transitions in the nervous system during amphibian metamorphosis. In: Metamorphosis: A Problem in Developmenta Biology. L.I. Gilbert and E. Frieden, eds. Plenum Press, New York, pp. 445-459.

Künemund, V., Jungalwala, F.B., Fischer, G., Chou, D.K.H., Kelihauer, G., and Schachner, M. (1988) The L2/HNK-1 carbohydrate of neural cell adhesion molecules is involved in cell interactions. $J$. Cell Biol., 106:213-223.

Lang, D.M., Rubin, B.P., Schwab, M.E., and Stuermer, C.A.O. (1995) CNS myelin and oligodendrocytes of the Xenopus spinal cord but not optic nerve are nonpermissive for axon growth. J. Neurosci., 15:99-109.

Lemke, G. and Chao, M. (1988) Axons regulate Schwann cell expression of the major myelin and NGF receptor genes. Development, 102:499-504

Maier, C.E, and Miller, R.H. (1995) Development of glial cytoarchitecture in the frog spinal cord. Dev. Neurosci. 17:149-159.

Mirsky, R. and Jessen, K.R. (1990) Schwann cell development and the regulation of myelination. Semin. Neurosci. 2:423-435.

Morgan, L., Jessen K.R., and Mirsky, R. (1991) The effects of cAMP on differentiation of cultured Schwann cells: Progression from an early phenotype $(\mathrm{O} 4+)$ to a myelin phenotype $(\mathrm{PO}+, \mathrm{GFAP}-$, 
N-cam-, NGF-receptor-) depends on growth inhibition. J. Cell Biol., 112:457-467.

Nieuwkoop, P.D. and Faber, J. (1956) Normal Table of Xenopus laevis (Daudin). North Holland, Amsterdam.

Nowakowski, R.S., Lewin, S.B., and Miller, M.W. (1989) Bromodeoxyuridine immunohistochemical determination of the length of the cell cycle and the DNA-synthetic phase for an anatomically defined population. J. Neurocytol. 18:311-318.

Pfeiffer, S.E., Warrington, A.E., and Bansal, R. (1993) The oligodendrocyte and its many cellular processes. Trends Cell Biol., 3:191-197.

Raff, M.C. and Miller, R.H. (1984) Glial cell development in the rat optic nerve. TINS, 7:469-472.

Raff, M.C., Miller, R.H., and Noble, M. (1983) A glial progenitor cell that develops in vitro into an astrocyte or an oligodendrocyte depending on culture medium. Nature, 303:390-396.

Ranscht, B., Clapshaw, P.A., Price, J., Noble, M., and Seifert, W. (1982) Development of oligodendrocytes and Schwann cells studied with an monoclonal antibody against galactocerebroside. Proc. Natl. Accid. Sci., USA, 79:2709-2713.

Reier, P.J. and Houlé, J.D. (1988) The glial scar: Its bearing on axonal elongation and transplantation approaches to CNS repair. Adv. Neurol., 47:87-138.

Reier, P.J. and Webster, H. deF. (1974) Regeneration and remyelination of Xenopus tadpole optic nerve fibres following transection or crush. J. Neurocytol., 3:591-618.

Schwab, M.E., Kapfhammer, J.P., and Bandtlow, C.E. (1993) Inhibitors of neurite growth. Annu. Rev. Neurosci., 16:565-595.

Schwalb, J.M., Gu, M., Stuermer, C.A.O., Bastmeyer, M., Hu, G., Boulis, M., Irvin, N. and Benowitz, L. (1996) Goldfish optic nerve glial secrete $\mathrm{AF}-1$, a peptide that stimulates retinal ganglion cells to regenerate their axons. Neuroscience, 72:901-910.

Sommer, I., and Schachner, M. (1981) Monoclonal antibodies (O1 to 04) to oligodendrocyte cell surfaces. An immunocytological study in the central nervous system. Dev. Biol., 83:311-327.

Steen, P., Kalghatgi, L., and Constantine-Paton, M. (1989) Monoclonal antibody markers for amphibian oligodendrocytes and neurons. $f$ Comp. Neurol., 289:467-480.

Taylor, J.S.H., and Gaze, R.M. (1985) The effects of the fibre environment on the paths taken by regenerating optic nerve fibres in Xenopus. J. Embryol. Exp. Morphol, 89:383-401.

Wanner, M., Lang, D.M., Bandtlow, C.E., Schwab, M.E., Bastmeyer, M., and Stuermer, C.A.O. (1995) Re-evaluation of the growth permissive substrate properties of goldfish optic nerve myelin. $J$. Neurosci., 15:7500-7508.

Wolburg, H. (1981) Myelination and remyelination in the regenerating visual system of the goldfish. Exp. Brain Res., 43:199-206. 